Review Article

\title{
Health Policy Interventions for the Effective Roll-Out of Novel Coronavirus (COVID- 19) Vaccine in India
}

\author{
Varun Singh
}

B.Pharm, MBA (Healthcare Management), Public Health Professional.

Former Consultant (Urban Health \& RCH Division), Ministry of Health and Family Welfare (Government of India), New Delhi. DOI: https://doi.org/10.24321/2454.325X.202006

\section{I $\quad \mathbf{N} \quad \mathbf{F} \mathbf{O}$}

E-mail Id:

varunsingh.mohfw@gmail.com

Orcid Id:

https://orcid.org/0000-0003-0264-1576

How to cite this article:

Singh V. Health Policy Interventions for the Effective Roll-Out of Novel Coronavirus COVID-19 Vaccine in India. Int J Preven Curat Comm Med 2020; 6(2): 4-11.

Date of Submission: 2020-09-10

Date of Acceptance: 2020-10-01

\section{$\begin{array}{llllllll}\mathbf{A} & \mathbf{B} & \mathbf{S} & \mathbf{T} & \mathbf{R} & \mathbf{A} & \mathbf{C} & \mathbf{T}\end{array}$}

The COVID-19 pandemic has indeed jeopardized the health status and socio-economic growth of the nations for decades. To protect the lives of humans and overcome economic slowdown, many vaccine candidates are at preclinical and clinical stages, with the expected use of the approved vaccine soon. Therefore, it is the time when nations need to pull up socks and carry-out preparatory activities to roll-out the COVID-19 vaccine. This article is an attempt to highlight possible health systems challenges and suggests few health policy interventions for the effective roll-out of the COVID-19 vaccine in India, whenever the vaccine gets regulatory approval for use.

Keywords: COVID-19, Coronavirus, SARS-COV-2, Vaccine, Vaccination, Health Systems, Health Policy, VPD, Universal Immunization Programme

\section{Introduction}

The coronavirus disease (COVID-19) caused by SARS-CoV-2 has started in December 2019 and within 8 months the disease has reported more than 28.02 million cases and has taken 0.90 million lives worldwide. India has reported 4.46 million cases and has reached at second rank in the world due to the high number of pandemic cases. ${ }^{1}$ Many vaccine manufacturers and research organizations are engaged in COVID-19 vaccine development and we all are waiting for the vaccine. But the question comes - Is the health system well strengthened and ready to roll-out the COVID-19 vaccine whenever the vaccine gets available? What preparatory activities need to be carried-out to rollout the COVID-19 vaccine? The article is discussing the possible health systems challenges during the COVID-19 vaccine introduction and also suggesting few health policy interventions/ strategies. The article may be helpful for the COVID-19 vaccine introduction in the Country, and for developing national guidelines on the COVID-19 vaccination.

\section{Methodology}

Desk review of literature, i.e. research articles and published guidelines. The Government of India (Gol) and international website providing COVID-19 data and situation reports.

\section{Discussion}

COVID-19 is a new disease with a high rate of infection and mortality around the globe. Therefore, healthcare delivery systems and available resources need to be assessed and strengthened for providing effective and safe COVID-19 vaccination, without compromising other ongoing public health programs mainly immunization. In India, immunization against Vaccine-Preventable Diseases (VPDs) is being carried out under India's Universal Immunization 
Programme. The UIP is a well-established program that vaccinates a cohort of 157 million estimated beneficiaries through about 10 million immunization sessions conducted each year with the help of a network of 27,000 cold chain points. Mentioning about UIP and vaccination against VPDs is significant here, as it will help us to understand whether the existing UIP mechanism and cold chain points can be used for COVID-19 vaccination in India or the Country needs some newly created infrastructure \& resources for vaccination against highly infectious pandemic disease, and in what circumstances. For developing the COVID-19 vaccine roll-out strategy, we must understand some common but significant differences between vaccination against Vaccine-Preventable Diseases vis-à-vis vaccination against COVID-19. ${ }^{2,3}$ These are:

\begin{tabular}{|c|c|}
\hline Vaccination against VPDs & Vaccination against COVID-19 \\
\hline $\begin{array}{l}\text { Intended to prevent Vaccine-Preventable } \\
\text { Diseases (VPDs) }\end{array}$ & $\begin{array}{l}\text { The vaccine will be used to treat highly infectious COVID-19 } \\
\text { disease }\end{array}$ \\
\hline $\begin{array}{l}\text { Target beneficiary belongs to a specific age } \\
\text { group i.e. } 0-5 \text { years age of children, } 10-16 \text { years } \\
\text { of adolescent and pregnant women }\end{array}$ & $\begin{array}{l}\text { No defined age-group of patients. Disease agent (SARS-CoV-2) } \\
\text { can infect individuals at any age through human-to-human } \\
\text { transmission }\end{array}$ \\
\hline $\begin{array}{l}\text { Do not require any specific protection measures } \\
\text { (Personal Protective Equipment (PPEs), Mask } \\
\text { etc) by health staffs, beneficiaries \& caregivers }\end{array}$ & $\begin{array}{l}\text { Health staffs, patients and caregivers need to follow defined } \\
\text { protection measures (PPEs, hand hygiene, sanitation, distancing } \\
\text { norms etc) }\end{array}$ \\
\hline $\begin{array}{l}\text { No test or vaccination is required for vaccinators, } \\
\text { health staffs, Field Level Workers (FLWs), } \\
\text { beneficiaries and caregivers }\end{array}$ & $\begin{array}{l}\text { COVID-19 testing \& vaccination of all staffs (FLWs, Vaccinators, } \\
\text { Cold Chain Handlers etc.) must be carried out to prevent } \\
\text { transmission among staffs and further spread in the population }\end{array}$ \\
\hline $\begin{array}{l}\text { Capacity building and training of health human } \\
\text { resource about VPDs \& immunization program } \\
\text { has been done many times, mostly using offline } \\
\text { training sessions and workshops }\end{array}$ & $\begin{array}{l}\text { For offline COVID-19 training, maintaining social distancing may } \\
\text { be a challenge and, if COVID-19 precautions are not followed } \\
\text { by trainers/ organizers, it may lead to transmission among } \\
\text { healthcare providers and further spread to the community. } \\
\text { On the other hand, the ability of FLWs to use the IT platform } \\
\text { and build required skills using the online training program, as } \\
\text { well as, participant's access to internet facility may need to be } \\
\text { considered for developing a better better training plan }\end{array}$ \\
\hline $\begin{array}{l}\text { For routine vaccination program against VPDs, } \\
\text { staffs are identified and assigned with the tasks }\end{array}$ & $\begin{array}{l}\text { Dedicated and trained vaccinators and support staffs need to be } \\
\text { assigned for COVID-19 vaccination }\end{array}$ \\
\hline $\begin{array}{l}\text { The existing surveillance system and AEFI } \\
\text { management is well in place to track the } \\
\text { beneficiary and provide needed care }\end{array}$ & $\begin{array}{l}\text { Strengthening of COVID-19 disease tracing, surveillance, } \\
\text { monitoring, and AEFI management system needs to be done }\end{array}$ \\
\hline $\begin{array}{l}\text { The cold chain system is established across } \\
\text { the country to ensure vaccine storage at the } \\
\text { recommended temperature }\end{array}$ & $\begin{array}{l}\text { The government needs to decide whether cold chain points } \\
\text { established under routine immunization program will be used } \\
\text { for the COVID-19 vaccine or not? If yes, what would be the } \\
\text { modus operandi? }\end{array}$ \\
\hline $\begin{array}{l}\text { House-to-house visits by FLWs have supported } \\
\text { the estimation of beneficiaries and community } \\
\text { mobilization activities. Fixed and outreach } \\
\text { sessions are carried out, with the provision of } \\
\text { waste management }\end{array}$ & $\begin{array}{l}\text { House-to-house visits may not be feasible for line-listing. The } \\
\text { use of IT platforms may be explored. The government needs } \\
\text { to decide whether COVID-19 vaccination can be done through } \\
\text { outreach sessions, fixed sessions, or both. Infrastructure for } \\
\text { COVID-19 vaccination such as CCEs, separate \& well-ventilated } \\
\text { vaccination site, patient queue management system (token or } \\
\text { electronic system) and, waste management facility (as COVID-19 } \\
\text { is highly infectious) etc. need to be identified or establish }\end{array}$ \\
\hline $\begin{array}{l}\text { Recording and reporting system are well in } \\
\text { place to monitor program coverage and other } \\
\text { activities }\end{array}$ & $\begin{array}{l}\text { Recording \& reporting formats/portal need to be prepared to } \\
\text { monitor coverage, vaccine utilization and other activities related } \\
\text { to COVID-19 vaccination }\end{array}$ \\
\hline
\end{tabular}


Print media (banners, posters, leaflets etc.) are mostly used for IEC and awareness generation

Several mechanisms are in place to monitor \& evaluate progress/vaccine coverage. India has provisions of monthly \& quarterly reports, HMIS \& MCTS portals, concurrent monitoring etc
Door to door visits by FLWs may not be feasible and the distribution of printed IEC materials (like leaflets) may not be appropriate considering the chance of infection transmission. AV media may need to be developed for IEC activities

Well-defined monitoring and evaluation processes need to be developed
We need to understand that the COVID-19 disease is very infectious (declared pandemic) with fast transmission and high mortality across global boundaries. Thus, introduction/ roll-out of the COVID-19 vaccine may require well-defined health systems strengthening activities and standard operating procedures. Few health policy interventions/ suggestions are presented herein that may help the program managers/ policymakers in devising COVID-19 vaccine introduction guidelines and initiating preparatory activities well in time.

\section{Health Policy Interventions \& Way Forward COVID- 19 Vaccine Availability}

$A$ race has begun among vaccine manufacturers. The government \& other funding agencies like BMGF, GAVI Alliance, partner agencies are playing a key role in the development of the COVID-19 vaccine. As per the WHO's draft landscape of COVID-19 candidate vaccines, 145 candidate vaccines are in the preclinical evaluation stage, and 35 candidate vaccines are at various clinical trial phases. ${ }^{4}$ There is no safe and approved vaccine in the global market yet. Even when the COVID-19 vaccine gets regulatory approval for use, initially there are strong chances of limited COVID-19 vaccine production, supply and availability. Therefore, the use of Personal Protective Equipment (PPEs), maintaining hand hygiene, following lockdown measures, isolation, quarantine, and social distancing norms must be adopted by the public as a part of their lives. For the time being, there is no harm to adopting the SOPs for COVID-19 management, ${ }^{5}$ issued by the government from time to time. Meanwhile, the Government may focus on strengthening COVID-19 testing by exploring the use of innovative rapid diagnostic kits as introduced during the EBOLA pandemic like Real-Star Filovirus Screen RTPCR Kit 1.0. Easily accessible testing facilities will help patients to identify the disease $\&$ take precautions in time, and also support health staff to prioritized patients for COVID-19 vaccination based on disease severity and take more appropriate decisions about the vaccination using available vaccine stock.

\section{Population Prioritization For COVID-I9 Vaccination}

Considering possibilities of limited manufacturing capacity
\& supply and more demand globally, sub-national and national level governments may need to prepare a priority list for COVID-19 vaccine administration. Unlike UIP, it may not be feasible to roll out the COVID-19 vaccination program in a phased manner or some specific geographical area because the disease is spreading at a fast pace across borders. Further, there is no specific age-group or community that is infected with the COVID-19 disease and it may not be practically possible to cover large populations and/or patients, using a limited quantity of vaccine, on a pan India basis. Also, we need to give more attention to cover severe COVID-19 patients.

Therefore, the priority list may help the policymakers and healthcare program managers to easily identify target beneficiaries and plan vaccination against COVID-19. It will also help us in reducing the chances of vaccine stockouts and wastage. The suggestive priority list may be like:

- Personnel involved in National Security: Indian army and police department

- Personnel involved in COVID-19 management (CORONA WARRIORS): Doctors, nurses, paramedical staff, FLWs, sanitation workers, vaccine cold chain handlers, etc.

- Population having low immunity or disease condition: Children, old-age person and, patients suffering from chronic health conditions - HIV/AIDS, Tuberculosis, Cancer etc

- Personnel involved in policymaking: Civil Servants, leaders etc

- Others: People living in slums \& containment zones, vulnerable populations

\section{Sustainability Issues Related To COVID-19 Vaccination}

There are limited manufactures that are at the final stage of clinical trial and only a few may get regulatory approval for vaccine production \& use, globally. However, the global demand for the vaccine is much high compared to the expected production capacity. High demand may lead to high vaccine prices or frequent stock-outs. Thus, in-house production capacity needs to be bolstered to deal with the demand-supply gap and ensure adequate availability of COVID-19 Vaccine at an affordable price and with less lead-time. 
Further, options to ensure financial sustainability may be looked at, as vaccinating large populations using Government funding may not be feasible in the long run. The cost of COVID-19 testing and vaccination may be covered under the Centre and/or State run universal health coverage schemes, the contribution from a privileged section of the society may be increased to collect tax revenue and finance COVID-19 treatment or, long term international funding support may be explored. Market shaping strategies, ${ }^{7}$ if efficiently followed, may be a fruitful way to control the vaccine pricing and availability now and in the future as well.

\section{Beneficiary Estimation and Vaccine Procurement}

The procurement of the COVID-19 vaccine must be done based on the estimated number of beneficiaries/ patients and cold chain capacity to avoid vaccine stock-out and wastage. The government may follow the bottom-up approach to identify the estimated number of beneficiaries (COVID-19 cases) and vaccine \& logistics requirements. Regular tracking of COVID-19 cases, symptoms, its geographical spread, mortality trend, etc. must be carried out supported by line-listing through a house-to-house survey or by self-help registration portal. Area-wise linelisting of the current COVID-19 patients and, if possible, the projected number of cases may be calculated using Artificial Intelligence (Al). A compiled list of estimated numbers of cases in the country, considering priority cases, may help the national government for placing procurement order. Secondly, the assessment of cold chain capacity will give information about the storage capacity of the procured vaccine.

\section{Vaccine Cold Chain and Logistics Management}

The prerequisite is to review the available supply chain and cold chain status, previous vaccine introduction experiences, vaccine supply, utilization \& wastage trend, and associated factors thereof. Use of Artificial Intelligence in assessing even a piece of simple but important information like lead time to vaccine supply from manufacturer, seasonal impact on vaccine utilization \& wastage, the trend of electricity breach in cold chain points, vaccine distribution issues, causes of vaccine wastage at Cold Chain Points (CCPs) \& vaccination site, etc. may help in planning supply chain and vaccine \& logistics management more efficiently.

Assessment of cold chain capacity must be started at all CCPs, considering the estimated number of COVID-19 patients, the requirement of vaccine doses, wastage, buffer stock, and lead time. For the COVID-19 vaccine, using the cold chain established for the Universal Immunization Programme (UIP) ${ }^{3}$ may not be safe as it may impose health hazards to healthy individuals, children, and pregnant women, if not managed well. Thus, States need to develop/ update the CCP-wise list of functional Cold Chain Equipment
(CCEs), as well as, list of CCEs kept as under repair, beyond repair, and condemned. Efforts must be made to repair the Cold Chain Equipment (CCEs) which are lying unused as under repair. These additional CCEs may be used for storing the COVID-19 vaccine after repair. Further, condemned CCEs must be cleared to get physical infrastructure and space. Requirements of vaccine carriers, cold boxes, and ice-packs must be assessed well in advance to avoid last hour managerial issues.

Besides, there is no approved COVID-19 vaccine so far thus we are not aware of vaccine characteristics but if the COVID-19 vaccine comes under Open Vial Policy, intending to save vaccine doses, cover more population and reduce wastage, the return of COVID-19 open vial or vaccine carrier to the UIP cold chain points may not be safe. Therefore, separate resources, CCPs \& infrastructure may need to be identified and/or established. The national and subnational governments may need to think of a provision to differentiate CCEs, Vaccine Carriers, Ice-packs, Cold Box, and other essential infrastructure that will be used for COVID-19 vaccination and UIP vaccination. Hence, specific color-coding/permanent COVID-19 stickers/some innovative symbols like biomedical hazards may be considered, with adequate provision to create awareness among health staff and the public.

\section{Human Resource Deployment and Training}

The sub-national government may need to conduct an assessment of HR (mainly trained vaccinators \& FLWs) availability for COVID-19 vaccination. The government may also require to develop a standard operating procedure (SOPs) for HR deployment for COVID-19 vaccination and Routine Immunization (RI). The policymakers and public health managers must chalk-out a plan considering:

- Whether existing HR under RI program can be used for $\mathrm{RI}$ and COVID-19 vaccination both? If yes, SOPs may be developed for the same with a focus on training, deployment plan, reporting, vaccination schedule, preventive measures against COVID-19, etc.

- If additional HR is required, SOPs need to be developed considering new hiring possibility, financial implications \& mechanism of capacity building of new HR/ vaccinators.

A suitable mechanism may also be adopted to train FLWs and health staffs on COVID-19 disease and vaccination. Virtual training may not work well till we provide access to internet facilities to FLWs \& other staff. Offline training may require specific protection measures as per Government guidelines. Also, the feasibility \& safety of FLWs to use transport to attend the offline training session at district/ block level facility may be considered. The sub-national government may also need to review the FLW's incentive payment status and ensure timely payment to them so 
that the program's backbone could be supported to meet their family expenses.

\section{Use of Information Technology for Vaccination Planning, IEC and Recording \& Reporting}

The Use of IT platforms may play a critical role in the management of COVID-19. Innovative, efficient, and affordable technology to test COVID-19 disease in less time will help to identify cases and provide timely treatment to patients. It may be a challenging task for FLWs to track each patient \& prepare a line-list, especially of the vulnerable group and migrant population, and mobilize them for COVID-19 vaccination. Therefore, an aadhar/OTP based registration on the self-help registration portal by a beneficiary to avail COVID-19 vaccination may be fostered in line with the U.P. Government's e-Pass system ${ }^{8}$ developed for issuing COVID-19 curfew passes.

The online system will reduce the burden of FLWs and may facilitate the health department in COVID-19 patient tracing, vaccination planning, paper-less recording \& reporting, IEC \& communication, and follow-up for subsequent doses in the future if required. However, the confidentiality of an individual's data must be maintained. The IT system will also help to monitor the utilization of vaccine doses and reduce wastage/pilferage of government supply. Health ID generated once can be used by the patient for login, address update, IEC materials, and Government notification. The selfregistration may best be suited to the literate population/ mobile users. But in villages/urban-wards, a help-desk may be operated to provide the facility to those who have no access to mobile or are uneducated.

A suggested flow-chart indicating the use of an IT platform for COVID-19 vaccination is given at Figure 1.

\section{Site Planning For COVID- 19 Vaccination}

Considering the limited availability of the COVID-19 vaccine at the starting phase and prioritization of the COVID-19 vaccine beneficiary, a fixed vaccination site at block/district hospital may serve the purpose unless the government wants to cover every COVID-19 case through outreach session. However, the sub-national government must be ready with a blueprint for organizing a fixed and/or outreach site for COVID-19 vaccination, based on the direction of the national government. District/block health staff may identify safe and well-ventilated COVID-19 vaccination sites, ensure adequate availability of PPEs \& hand-washing facility/sanitizers, adopt social distancing by limiting the number of caregivers by using token system/queue. Instead of a 'One-Size-Fits-All' strategy, a 'Tailored based approach' may be followed for the planning of COVID-19 vaccination. ${ }^{9}$

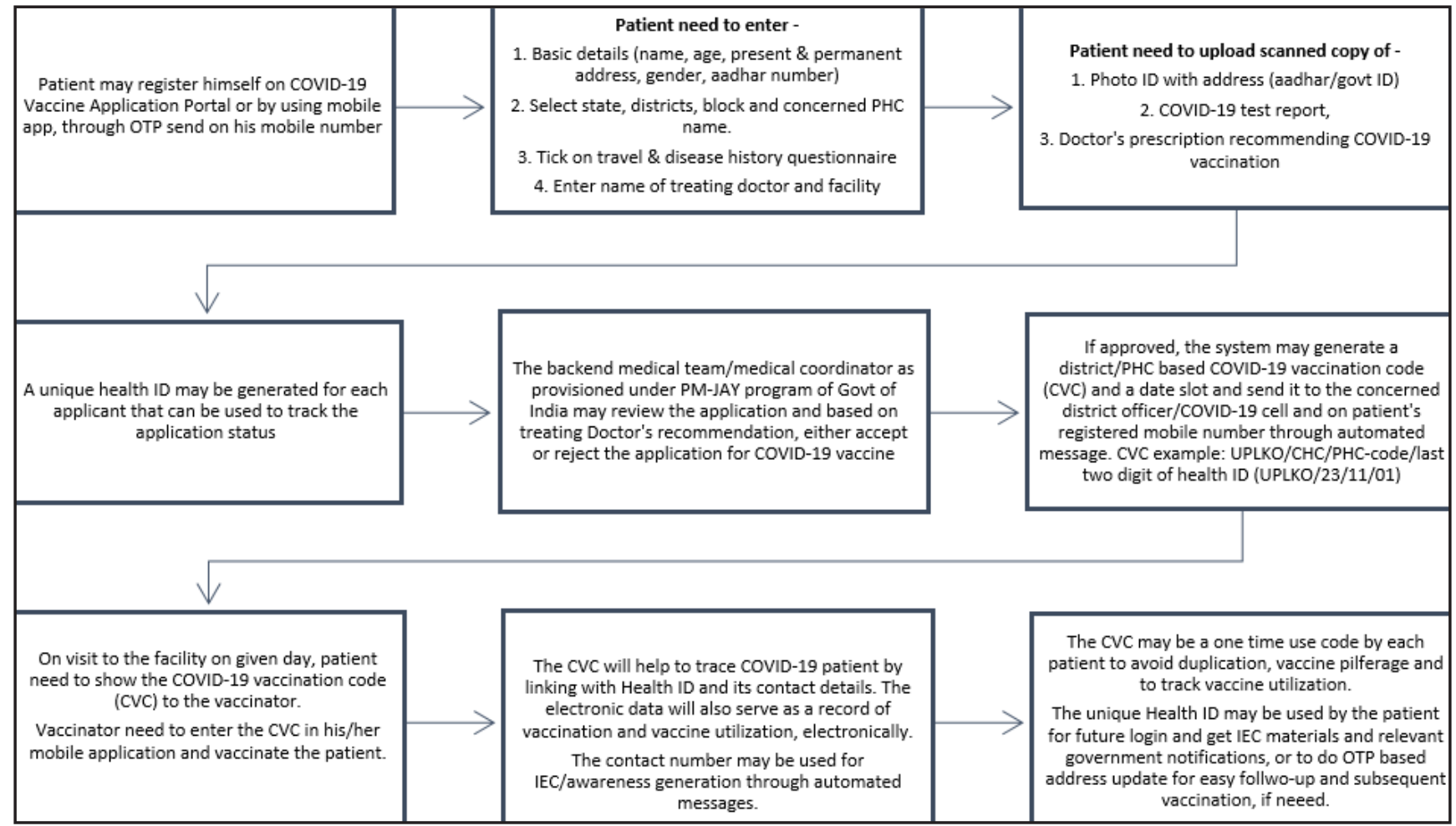

Figure I 


\section{COVID- 19 Vaccination in Urban Areas}

India's urban areas are facing diverse issues and challenges. Each urban area has pockets of a vulnerable population. The urban area also faces infrastructural \& environmental issues and occupational health hazards. ${ }^{10}$ To initiate COVID-19 vaccination, priority action points may include assessment of disease distribution among vulnerable populations considering residential vulnerability (people living in slums, roadsides, underpass), occupational vulnerability (ragpickers, construction workers, domestic workers, commercial laborers) and, social vulnerability (patient with HIV/AIDS, mental health issues, transgenders, etc.). This vulnerability assessment and disease tracing would help in better planning and organizing COVID-19 vaccination sessions in urban areas. If we do not conduct an assessment and exclude potential suspect/ confirm cases in-line listing for COVID-19 vaccination, the chances of disease transmission will certainly become high as these vulnerable groups and left out a section of the society are more exposed to the disease environment and poor health, sanitization, nutrition \& hygiene.

The self-registration by patients on the self-help portal to avail COVID-19 vaccine, as suggested above, may not work well in urban slums, vulnerable groups, and uneducated population groups. Therefore, a special focus may be needed to establish a help desk and assign the task of line listing and registering COVID-19 patients to the FLWs (urban ASHA and Anganwadi workers). However, in certain urban areas/ cities, the position of urban ASHA is still vacant causing more burden on AWWs and ANMs. The state needs to assess the position of FLWs so that adequate arrangements could be done with the help of local NGOs and other private agencies under the public-private partnership (PPP) model. The medical, nursing, and pharmacy colleges may be contacted to fill the programmatic and infrastructural gaps and to cover the population assuring the least possibility of missed/ left out COVID-19 patients.

Besides to ensure the effective service delivery for COVID-19 vaccination, convergence with other government departments like urban local bodies, drinking water \& sanitation, housing, and urban poverty alleviation, woman \& child development, education, home affairs, etc. , as well as, with various agencies (private health facilities, ESI, army \& railway hospitals) working in the sector must be promoted. Corporate organizations, educational institutions, residential societies, and media may be roped in to facilitate awareness generation using IEC, tracing of COVID-19 cases by ensuring the installation of the Aarogya Setu app \& monitoring of vitals and, referral for COVID-19 vaccination by providing information to the concerned health officials/ district administration.

\section{COVID-I9 Vaccination in Educational Institutions}

School health program plays a vital role in immunization (like in Measles-Rubella vaccine) of children. ${ }^{11}$ But due to the COVID-19 pandemic, classes in educational institutions have been restricted and online studies are provisioned. No physical presence of the students may lead to a high burden on FLWs to trace \& mobilize school and out-of-school children for COVID-19 testing \& vaccination. We also need to understand that disruption of classroom education, group-learning, and physical activities may not be good for the mental \& physical development of students, as well as, the education system in long run. Therefore, we must have SOPs for COVID-19 vaccination to students at educational institutions whenever classes resume. But more care and precautions will be required to prevent COVID-19 transmission from student-to-student, student-to-teaching staff and/or vice-versa. Thus, the primary action must be to strengthen the identification of COVID-19 cases, conduct testing, and vaccination either in educational institutions itself or at designated health facilities as per the government's instruction. The consent of parents/ students may be sought. The mandatory vaccination of staff may be considered to avoid the chances of infection among students. Involvement of the education department, National Cadet Corps, Nehru Yuva Kendra, Lions club, IMA, IAP, other educational systems such as Madrasa, Missionary schools, etc. may help to reach each child.

\section{Strengthening of COVID-I 9 Surveillance System and Management of Adverse Events}

The government must focus on strengthening surveillance of COVID-19 cases and develop SOPs for managing the adverse event after COVID-19 vaccination if reported. Unlike RI, reported adverse events in COVID-19 patients may need a different approach to provide immediate treatment, referral, and reporting of cases. The use of Artificial Intelligence for data analysis may be initiated since the program beginning to monitor the effectiveness of vaccination and identify/ compile the causes associated with the reported adverse events.

\section{Community Mobilization for Covid-19 Vaccination}

For community mobilization and monitoring, the use of mobile calls or messages may be promoted. If needed, only assigned supervisor or staff of supporting agencies may be allowed to visit vaccination sites for monitoring and support. The involvement of religious and political leaders, media, and local influential persons, especially in areas where the community is against COVID-19 testing and treatment, 
may ensure safety, security and much needed support to healthcare workers during field activity. There may be possible chances of community refusal/ vaccine hesitancy, therefore, an evidence-based approach may be adopted to create awareness and to inform the community about the benefits of COVID-19 testing \& vaccination. Appropriate safety measures for FLWs including district/ block helpline number, an immediate response from police may need to be considered to protect FLWs from violence by unsocial elements during COVID-19 testing \& treatment and during community visit to follow-up suspected/ confirmed cases. ${ }^{9}$

\section{Waste Management during Covid- I 9 Vaccination}

The Biomedical Waste Management including vaccination waste is managed as per the Biomedical Waste Management Rules, 2016,12 and the Biomedical Waste Management (Amendment) Rules, 2019. ${ }^{13}$ The Ministry of Health and Family Welfare, India has also issued guidelines from time to time for the management of waste generated during immunization services either as a separate guidelines like Guidelines for Handling, Treatment and Disposal of Waste or as a part of other guidelines such as Immunization Handbook for Medical Officers ${ }^{2}$ and national operational guidelines on Rotavirus vaccine introduction ${ }^{14}$ PCV introduction ${ }^{15}$ and MR introduction ${ }^{11}$ etc. There has been a specific focus on vaccination/immunization waste management for decades. But, the National EVM Assessment, 2018 report ${ }^{16}$ identified waste management as a major service delivery gap and has mentioned - "Immunization Waste Disposal facilities and procedures are not in accordance either with WHO and/ or with national norms". Similar gaps have been identified during Common Review Mission and UIP review as well. It is the time when we all must come together, understand the associated health \& environmental hazard of BMW and, act responsibly to overcome the waste management issues. COVID-19 is a highly infectious disease and waste generated during COVID-19 vaccination as well as used PPEs must be discarded as per the guidelines without fail. Otherwise, unknowingly we will act as a catalyst to disease transmission among healthy individuals and patients with chronic health problems like HIV/AIDS and Tuberculosis, etc. The waste management facility must be reviewed at district and sub-national levels and suitable arrangements must be done to ensure handling, collection, segregation, transportation, treatment, and disposal of waste and used PPEs generated during COVID-19 vaccination. Public-Private Partnership must be explored taking into consideration that the agency must not mix infectious COVID-19 vaccination waste with hospital waste and RI waste. We must take the COVID-19 vaccination program as an opportunity to fill the existing biomedical waste management gaps.

\section{Conclusion}

The article may act as a policy tool and may support the public health managers \& policymakers to plan and roll-out the COVID-19 vaccination in India, whenever the vaccine gets regulatory approval for use. The suggestions may also be suitably incorporated in national operational guidelines on the COVID-19 Vaccination Program. Interventions suggested herein like population prioritization for the COVID-19 vaccine, use of artificial intelligence \& IT etc., may provide insight to higher authorities. Other nations may also review the health policy interventions suggested herein while devising the policy to rollout the COVID-19 vaccine. Considering the severity of the pandemic, we all need to be prepared well in time to avoid last time hurry.

\section{Conflicts of Interest: None}

\section{References}

1. Worldometer. COVID-19 Coronavirus Pandemic. 10 Sep. 2020. Available from: http://www.endmemo. com/sconvert/onemillion.php.

2. Ministry of health and family welfare, Government of India. Immunization Handbook for Medical Officers, 2017. Available from: https://nhm.gov.in/New Updates_2018/NHM_Components/Immunization/ Guildelines_for_immunization/Immunization_ Handbook_for_Medical_Officers\%202017.pdf.

3. Ministry of health and family welfare, Government of India. Guidelines on Universal Immunization Program. Available from: https://main.mohfw.gov. in/sites/default/files/5628564789562315.pdf.

4. WHO, a Draft landscape of COVID-19 candidate vaccines. 9 Aug. 2020. Available from: https://www. who.int/publications/m/item/draft-landscape-of-covid19-candidate-vaccines.

5. DGHS, Ministry of health and family welfare, Government of India. SOPs for transporting a suspected/confirmed case of COVID-19. Available from: https://www.mohfw.gov.in/pdf/Standard Operating Procedure SOP for transporting a suspector confirmedcase of COVID19.pdf.

6. National health authority, Government of India. Health Benefits Packages. Available from: https://pmjay.gov. in/resources/documents.

7. GAVI- The Vaccine Alliance, Market Shaping. Available from: https://www.gavi.org/our-alliance/market-shaping.

8. Government of Uttar Pradesh, COVID-19 e-Pass system. Available from: http://164.100.68.164/upepass2/ Apply.aspx.

9. Singh V. The Effect of COVID-19 Pandemic on Immunization Services in India - Possible Challenges and way forward. Epidem Int 2020; 5(2): 53-60. Available from: http://medical.advancedresearchpublications. com/index.php/EpidemInternational/article/view/355

10. Ministry of health and family welfare, Government of 
India. Operational Guidelines for Conducting Outreach Sessions in Urban Areas, 2015. Available from: https:// nhm.gov.in/images/pdf/NUHM/Outreach_Sessions_ in_Urban_Areas.pdf.

11. Ministry of health and family welfare, Government of India. National operational guidelines for the introduction of the measles-rubella vaccine. Delhi: 2017. Available from: http://origin.searo.who.int/india/topics/measles/measles_rubella_vaccine_guidelines.pdf.

12. Ministry of environment, forest, and climate change. Government of India. Biomedical Waste Management Rules, 2016. Available from: https://dhr.gov.in/sites/ default/files/Bio-medical_Waste_Management_ Rules_2016.pdf.

13. Ministry of environment, forest, and climate change. Government of India. Biomedical Waste Management (Amendment) Rules, 2019. Available from: https:// kspcb.gov.in/BMW-(A)Rules-2019.pdf.

14. Ministry of health and family welfare, Government of India. National operational guidelines for the introduction of the rotavirus vaccine in UIP. Delhi: March 2019. Available from: https://nhm.gov.in/New Updates_2018/NHM_Components/Immunization/ Guildelines_for_immunization/Operational_ Guidelines_for_Introduction_of_Rotasiil_in_UIP.pdf.

15. Ministry of health and family welfare, Government of India. National operational guidelines for the introduction of Pneumococcal Conjugate Vaccine. Delhi: 2017. Available from: https://nhm.gov.in/New Updates_2018/NHM_Components/Immunization/ Guildelines_for_immunization/Operational_ Guidelines_for_PCV_introduction.pdf

16. National EVM Assessment 2018, Ministry of Health and Family Welfare. Available from: https://nhm. gov.in/New_Updates_2018/NHM_Components/ Immunization/Guildelines_for_immunization/ National_EVM_Assessment_Report_2018.pdf. 